\title{
PREVALENCE OF PERSISTENT DEPRESSIVE DISORDER AMONG PSYCHIATRIC OUTPATIENTS IN AL-AZHAR UNIVERSITY HOSPITALS
}

By

\section{Ahmed Saad Hassanein Youssef, Mohamed Ahmed Lotfy Kamal Al- Mahdy and Mohamed Mohamed Ali El-Sheikh}

\author{
Department of Psychiatry, Faculty of Medicine, Al-Azhar University, Cairo
}

Corresponding author: Ahmed Saad Hassanein,

Mobile: 01003599117, E-mail: dr.a7medsa3d1409@gmail.com

\begin{abstract}
Background: Persistent Depressive Disorder (PDD) has higher comorbidity rates and negative impact on different aspects of patient's life than episodic, non-chronic, Major Depressive Disorder. To our knowledge, no recent studies about PDD held in Egypt.

Objective: To estimate the prevalence and comorbidities of PDD and its subtypes among a sample of psychiatric outpatients.

Patients and methods: This was an observational, cross-sectional, non-randomized study. It was conducted in Al-Azhar University hospitals over the period from October 2109 till July 2020. Sample of 111 adult patients, aging $(18-65)$ years old from both genders, who are visiting the psychiatric outpatient for whatever complaint are collected consecutively. Prior to applying the tests, patients with the diagnosis of bipolar I and II disorders, psychotic disorders, acute suicidality, intellectual disabilities, organic mental disorders, or history of brain surgery were excluded from the study. Those patients underwent detailed clinical examination, patient health questionnaire and persistent depression screener.
\end{abstract}

Results: Prevalence of PDD among our sample was 36.9\% ( $\mathrm{n}=41)$ with late onset in $55 \%(\mathrm{n}=22)$. The subtype "intermittent major depressive episodes with current episode" was the most prevalent subtype in $61 \%(\mathrm{n}=25)$. post-traumatic stress disorder and specific phobia were significantly more common in PDD cases $(\mathrm{P}=0.001, \mathrm{P}=0.41$ respectively), while panic disorder was significantly less common $(\mathrm{P}=0.013)$. All other comorbidities were equally distributed among PDD and non-PDD cases.

Conclusion: PDD was a highly prevalent psychiatric disorder and may be masked by comorbid psychiatric disorders even MDD. These findings might promote psychiatrists to give more attention to PDD because of its impact on prognosis of other disorders and patient's quality of life.

Keywords: persistent depressive, dysthymia, chronic depression, psychiatric comorbidity.

\section{INTRODUCTION}

Depression is the most prevalent mental disorder affecting over three hundred twenty-two million people worldwide. It is ranked by World Health Organization (WHO) as the single largest contributor to global disability $(7.5 \%$ of all years lived with disability in 2015). It is also the major contributor to suicide deaths, which number close to 800000 cases annually. It is more common among females than males $(5.1 \%, \quad 3.6 \%$ respectively). It is the fifth cause of disability on Egypt in 2017 (WHO, 2017). 
If depressive symptoms persist for 2 years or longer, depression is considered to be chronic or, according to Diagnostic and Statistical Manual of Mental Disorders, 5th edition (DSM-5): Persistent Depressive Disorder (PDD) or Dysthymia, representing a consolidation of the DSMIV definitions of chronic major depression and dysthymic disorder. PDD incorporates four different clinical subtypes: (1) pure dysthymic syndrome; (2) persistent major depressive episode (MDE);

intermittent MDE with current episode; (4) intermittent MDE without current episode (APA, 2013).

Patients with PDD have an earlier onset and higher comorbidity rates than patients with non-chronic depression, and are less responsive to traditional pharmacological or psychological treatments (Guhn et al., 2019). It is a major public health problem regarding to its frequency and its impact. In the general population, it has an estimated lifetime prevalence of $4.6 \%$ in modern study (Murphy and Byrne, 2012), or up to $6.4 \%$ in old studies depending on the diagnostic criteria employed, while in psychiatric population may reach $36 \%$ (Schramm et al., 2020). In comparison to individuals with nonchronic -episodic- major depressive disorder, those with persistent depressive disorder are at higher risk for psychiatric comorbidities in general (Wiersma et al., 2011 and APA, 2013), and for anxiety disorders, substance use disorders and personality disorders. They are more liable for greater social impairment and lower quality of life, more impaired physical health, and more frequent suicide attempts and hospitalizations (Klein et al., 2015).
Also patients with PDD have difficulties in their personal relationships, work, education, financial, sexual, and leisure activities (Schramm et al., 2020).

Despite this high prevalence, there are several studies showing that patients with dysthymia are not diagnosed and consequently not treated appropriately. This difficulty in establishing a diagnosis of dysthymia is related to the presence of an underlying depression or its association with another disorder, often being the reason for the main complaint. However, despite the high levels of comorbidity, dysthymia is frequently the main underlying disorder (Ventriglio et al., 2020).

It is possible that many psychiatrists consider major depression and panic to represent the major focus of treatment presenting clinically, and thereby may miss the opportunity to treat the underlying PDD. There is a risk in paying attention predominantly to somatic or anxiety complaints of the patients, considering the depressive symptoms as a secondary reaction, instead of the main disorder, which may lead to treatment error (Klein and Black, 2013).

Patients with chronic depression seem to respond better to specific forms of therapy, e.g. the cognitive behavioral analysis system of psychotherapy (CBASP) than to unspecified forms of therapy. So it is necessary to identify chronic courses of depression since treatment of chronically depressed patients seems to be more successful when their particular needs and deficits, such as interpersonal problems and comorbidity with personality disorders, are directly addressed (Brinkmann et al., 2019). 
Psychiatrists with a horizontal perspective are more likely to diagnose Major Depressive Disorder, while those with a vertical perspective are more likely to identify chronic depression (i.e. PDD) in the majority of depressive patients. The incorporation of both perspectives into DSM-5 in a complementary way will possibly enhance the insight into depressive disorders and improve treatment results (Ildirli et al, 2015).

A knowledge gap remains regarding the lifetime characteristics and correlates of chronic depression and the reliability of the PDD concept itself (Nübel et al., 2020).

In Egypt, few studies discussed dysthymia, to our knowledge there are no recent studies on the new concept of PDD.

The present work aimed to estimate the prevalence and comorbidities of Persistent Depressive Disorder (Dysthymia) and its subtypes among psychiatric outpatients in Al-Azhar University Hospitals.

\section{PATIENTS AND METHODS}

This study was designed as an observational, cross-sectional, nonrandomized study. It was conducted in AlAzhar University Hospitals (Al-Hussein and Sayed Galal Hospitals) over the period from October 2109 till July 2020.

This study was approved by the Ethics Board of Al-Azhar University.

Sample of 111 patients was collected by consecutive sampling, from psychiatric outpatient clinics satisfying all the inclusion criteria: Psychiatric Outpatient and their ages ranging between $18-65$ years. Patients are free from exclusion criteria: Cognitive Impairment, Bipolar Affective Disorder, Organic mental disease, history of neurosurgery and Psychotic Disorders. Those patients underwent:

1. Detailed clinical examination by welltrained senior psychiatrist including mental state examination (MSE) regarding DSM-5 criteria. The psychiatric interview will be based on the Structured Clinical Interview for DSM (Brinkmann et al., 2019).

2. Patient Health Questionnaire-9: A Selfreport questionnaire can provide an accurate diagnosis that is equally valid when compared to the structured clinical interview. PHQ-9 is one of the most widely used clinical diagnostic instruments. It is valid and reliable in detecting depression. In many studies, the Arabic version was used, and its validity and reliability were assured (Alhadi et al., 2017).

3. Persistent depression screener: A paper-and-pencil screening composed of one question. It is to be administered following a self-rating instrument for depressive symptoms (e.g. PHQ-9). The PDS is based on the DSM-5 criteria for PDD and focusses on criterion for chronicity of the symptoms (Brinkmann et al., 2019).

\section{The screening question read:}

"The previous questions covered various symptoms of depression. Now, please consider: When was the last period of two months or longer that you were not impaired by these symptoms?"

The following response options were given: 


\section{AHMED SAAD HASSANEIN YOUSSEF et al.,}

a. Less than a year ago.

b. More than a year but less than 2 years ago.

c. More than 2 years but less than 5 years ago.

d. More than 5 years but less than 10 years ago.

e. More than 10 years ago.

\section{Answer Keys:}

(a) and (b) indicate a likely absence of PDD ("PDS negative").

(c), (d) and (e) indicate a likely presence of PDD ("PDS positive").

\section{Statistical Analysis:}

The collected data were revised, coded, tabulated and introduced to a PC using Statistical package for Social Science (IBM Corp., Version 20.0. Armonk, NY: IBM Corp). Data was presented and suitable analysis was done according to the type of data obtained for each parameter.

- Description of quantitative variables as mean and SD.

- Description of qualitative variables as number and percentage.

- Chi-square test was used to compare qualitative variables.

- $\mathrm{P} \leq 0.05$ was considered significant. 


\section{RESULTS}

Age of the included patients was $32.23 \pm 9.22$ years (mean \pm SD) ranging from 19 to 65 years. Male patients were $55(49.5 \%)$ while females were 56 $(50.5 \%)$. Majority of patients were singles $57(51.4 \%)$. Offspring ranged between $0-3$ with majority of 2 offspring in $24(52.2 \%)$ of non-single cases. Most (66.7\%) of sample had university education and 73 $(65.8 \%)$ were jobless. Urban residents were $75(67.6 \%)$ and nonsmokers were the majority $85(76.6 \%)$ (Table 1).

Table (1): Baseline characteristics of the sample

\begin{tabular}{|c|c|c|c|c|c|}
\hline \multirow{2}{*}{\multicolumn{2}{|c|}{$\begin{array}{l}\text { Variables } \\
\text { Age }(\text { mean } \pm \text { SD) } \\
\end{array}$}} & \multicolumn{2}{|c|}{ whole sample } & \multicolumn{2}{|c|}{ PDD } \\
\hline & & 32.23 & 9.22 & 34 & 10 \\
\hline & & $\mathbf{N}$ & $\%$ & $\mathbf{N}$ & $\%$ \\
\hline \multirow{2}{*}{ Sex } & Male & 55 & $49.5 \%$ & 15 & $36.6 \%$ \\
\hline & Female & 56 & $50.5 \%$ & 26 & $63.4 \%$ \\
\hline \multirow{6}{*}{ Marital state } & Single & 57 & $51.4 \%$ & 25 & $61.0 \%$ \\
\hline & Married & 37 & $33.3 \%$ & 9 & $22.0 \%$ \\
\hline & Divorced & 8 & $7.2 \%$ & 5 & $12.2 \%$ \\
\hline & Widow & 1 & $0.9 \%$ & 1 & $2.4 \%$ \\
\hline & Separated & 0 & $0.0 \%$ & 0 & $0.0 \%$ \\
\hline & Engaged & 8 & $7.2 \%$ & 1 & $2.4 \%$ \\
\hline \multirow{4}{*}{ Offspring } & 0 & 6 & $13.0 \%$ & 3 & $20.0 \%$ \\
\hline & 1 & 6 & $13.0 \%$ & 2 & $13.3 \%$ \\
\hline & 2 & 24 & $52.2 \%$ & 5 & $33.3 \%$ \\
\hline & 3 & 10 & $21.7 \%$ & 5 & $33.3 \%$ \\
\hline \multirow{4}{*}{ Educational level } & Illiterate & 0 & $0.0 \%$ & 0 & $0.0 \%$ \\
\hline & Low & 3 & $2.7 \%$ & 1 & $2.4 \%$ \\
\hline & Moderate & 34 & $30.6 \%$ & 14 & $34.1 \%$ \\
\hline & High & 74 & $66.7 \%$ & 26 & $63.4 \%$ \\
\hline \multirow{2}{*}{ Job } & Employed & 38 & $34.2 \%$ & 15 & $36.6 \%$ \\
\hline & Unemployed & 73 & $65.8 \%$ & 26 & $63.4 \%$ \\
\hline \multirow{2}{*}{ Residency } & Rural & 36 & $32.4 \%$ & 13 & $31.7 \%$ \\
\hline & Urban & 75 & $67.6 \%$ & 28 & $68.3 \%$ \\
\hline \multirow{2}{*}{ Smoking } & Nonsmoker & 85 & $76.6 \%$ & 32 & $78.0 \%$ \\
\hline & Smoker & 26 & $23.4 \%$ & 9 & $22.0 \%$ \\
\hline
\end{tabular}

Among the study sample of 111 psychiatric outpatients, PDD was found in 41 cases (36.9\%) (Table 2).

Table (2): Prevalence of PDD

\begin{tabular}{|c|c|c|c|}
\hline \multicolumn{2}{|c|}{ Diagnosis } & Number & Percentage \\
\hline \multirow{2}{*}{ PDD } & No & 70 & $63.1 \%$ \\
\cline { 2 - 4 } & Yes & 41 & $36.9 \%$ \\
\hline
\end{tabular}

The onset was early in $19(46.3 \%)$ and late in $22(53.7 \%)$. The subtype "intermittent major depressive episodes, with current episode" was the most prevalent in the sample $(61 \%)$ followed by the "pure dysthymic syndrome, $17.1 \%$ " then "intermittent major depressive episodes, without current episode, 14.6\%" (Table 3). 
Table (3): PDD onset and subtypes

\begin{tabular}{|l|l|c|c|}
\hline Onset - Subtypes & N & \% \\
\hline \multirow{3}{*}{ Onset } & Early, before age 21 years & 19 & $46.3 \%$ \\
\cline { 2 - 4 } & Late, at age 21 years or older & 22 & $53.7 \%$ \\
\hline \multirow{4}{*}{ Subtypes } & pure dysthymic syndrome & 7 & $17.1 \%$ \\
\cline { 2 - 4 } & persistent major depressive episode & 3 & $7.3 \%$ \\
\cline { 2 - 4 } & $\begin{array}{l}\text { intermittent major depressive episodes, with } \\
\text { current episode }\end{array}$ & 25 & $61.0 \%$ \\
\cline { 2 - 4 } & $\begin{array}{l}\text { intermittent major depressive episodes, } \\
\text { without current episode }\end{array}$ & 6 & $14.6 \%$ \\
\hline
\end{tabular}

Post-traumatic stress disorder (PTSD) and specific phobia were significantly more common in PDD cases $(\mathrm{P}=0.001$, $\mathrm{P}=0.41$ respectively) while panic disorder was significantly less common $(\mathrm{P}=0.013)$. All other comorbidities were equally distributed among PDD and non PDD cases. Generalized anxiety disorder (GAD), (PTSD) and ObsessiveCompulsive Personality Disorder (OCPD) the most prevalent comorbidities (Table 4).

\section{Table (4): PDD relation with other comorbidities}

\begin{tabular}{|l|l|l|l|l|l|}
\hline \multirow{2}{*}{ Gomorbid disorders } & \multicolumn{2}{|l|}{ Gon-PDD (N=70) } & \multicolumn{2}{l|}{ PDD (N=41) } & \multirow{2}{*}{ P } \\
\cline { 2 - 5 } & $\mathbf{N}$ & $\mathbf{\%}$ & $\mathbf{N}$ & $\mathbf{\%}$ & \\
\hline Generalized Anxiety Disorder & 28 & $40.0 \%$ & 18 & $43.9 \%$ & 0.687 \\
\hline Post-Traumatic Stress Disorder & 2 & $2.9 \%$ & 9 & $22.0 \%$ & $\mathbf{0 . 0 0 1}$ \\
\hline Obsessive compulsive PD & 8 & $11.4 \%$ & 5 & $12.2 \%$ & 0.904 \\
\hline Obsessive Compulsive Disorder & 11 & $15.7 \%$ & 4 & $9.8 \%$ & 0.376 \\
\hline Social Anxiety Disorder & 6 & $8.6 \%$ & 4 & $9.8 \%$ & 0.833 \\
\hline Specific Phobia & 1 & $1.4 \%$ & 4 & $9.8 \%$ & $\mathbf{0 . 0 4 1}$ \\
\hline Avoidant Personality Disorder & 3 & $4.3 \%$ & 4 & $9.8 \%$ & 0.252 \\
\hline Borderline Personality Disorder & 4 & $5.7 \%$ & 4 & $9.8 \%$ & 0.427 \\
\hline Substance Use Disorder & 11 & $15.7 \%$ & 3 & $7.3 \%$ & 0.198 \\
\hline Somatic Symptom Disorder & 3 & $4.3 \%$ & 3 & $7.3 \%$ & 0.507 \\
\hline Dependent Personality Disorder & 2 & $2.9 \%$ & 2 & $4.9 \%$ & 0.581 \\
\hline Panic Disorder & 13 & $18.6 \%$ & 1 & $2.4 \%$ & $\mathbf{0 . 0 1 3}$ \\
\hline Paranoid Personality Disorder & 2 & $2.9 \%$ & 1 & $2.4 \%$ & 0.896 \\
\hline Histrionic Personality Disorder & 5 & $7.1 \%$ & 1 & $2.4 \%$ & 0.290 \\
\hline Alcohol Use Disorder & 2 & $2.9 \%$ & 0 & $0.0 \%$ & 0.275 \\
\hline Agoraphobia & 5 & $7.1 \%$ & 0 & $0.0 \%$ & 0.080 \\
\hline Illness Anxiety Disorder & 4 & $5.7 \%$ & 0 & $0.0 \%$ & 0.119 \\
\hline Conversion Disorder & 1 & $1.4 \%$ & 0 & $0.0 \%$ & 0.442 \\
\hline Adult ADHD & 2 & $3.8 \%$ & 0 & $0.0 \%$ & 0.298 \\
\hline Trichotillomania & 1 & $1.4 \%$ & 0 & $0.0 \%$ & 0.442 \\
\hline Schizoid Personality Disorder & 2 & $2.9 \%$ & 0 & $0.0 \%$ & 0.275 \\
\hline Narcissistic PD & 5 & $7.1 \%$ & 0 & $0.0 \%$ & 0.080 \\
\hline Antisocial Personality Disorder & 2 & $2.9 \%$ & 0 & $0.0 \%$ & 0.275 \\
\hline Unspecified PD & 1 & $1.4 \%$ & 0 & $0.0 \%$ & 0.442 \\
\hline
\end{tabular}




\section{DISCUSSION}

In our sample, the female to male ratio (2:1 while being $1: 1$ in the whole sample) correspond to a well-established information obtained from many previous studies which state that the rate of chronic depression is almost twice as great in women than in men (Schramm et al., 2020).

Regarding employment status, our findings are in line with other studies which demonstrated that patients with chronic depression have a higher risk of employment problems, including decreased productivity and increased unemployment. A study found that at 6 months follow up, $14 \%$ of patients with dysthymia were newly unemployed, compared with $2 \%$ new unemployment in the control group and 3\% new unemployment in a group with rheumatoid arthritis. It is observed that there is an inverse relationship between the prevalence of mental disorders and functionality of the patients (Hellerstein et al., 2017).

Prevalence of PDD among psychiatric outpatients in this study $(36.9 \%)$ is close to some previous studies, particularly those found rates of dysthymia at around $36 \%$ among DSM III psychiatric patients, but higher than some other studies those fount it to vary from 26 to $36 \%$ in psychiatric populations (Murphy \& Byrne, 2012 and Markkula et al., 2015). These differences may be due to an evolution and expansion of the concept of PDD.

The chronic characteristic of dysthymia is associated with higher rates of prevalence mainly because it is well established that any factor that elevates the duration of a disorder raises its prevalence and, consequently, the chances of identification of a case.

The majority of our PDD patients had a late onset of the disorder (55\%), a finding which was in conflicts with other studies (Schramm et al., 2020).

This discrepancy could be explained by the difference in the study sample by changing and expanding the concept of PDD and because these symptoms have become a part of the individual's day-today experience, particularly in the case of early onset. They may not be reported unless the individual is directly prompted (APA, 2013).

The most prevalent subtype of PDD was intermittent major depressive episodes, with current episode by about $61 \%$, which was in line with the assumption that the leading cause of patients to seek psychiatric help was acute moderate to severe complaints rather than chronic mild ones. In a previous study it is estimated that $75 \%$ of people with dysthymia meet criteria for at least 1 major depressive episode, referred to as double depression (Wenzel, 2017). To our knowledge, no studies examined prevalence of PDD subtypes.

PDD patients had high comorbidity rates with generalized anxiety disorder, post-traumatic stress disorder and obsessive-compulsive personality disorder. In comparison to Non-PDD cases post-traumatic stress disorder and specific phobia were significantly more common in PDD cases, while panic disorder was significantly less common. All other comorbidities were equally distributed among PDD and non PDD cases. 
Regarding comorbid PDs, cluster C PDs was the most prevalent by 11 diagnoses, then cluster B by 6 diagnoses. The most prevalent PD was OCPD then avoidant and borderline. This finding showed a minor difference with other previous studies which count avoidant PD as the most prevalent PD (Erkens et al., 2018). This minor discrepancy may be due to small sample size and sociocultural factors.

In a previous epidemiological studies, common psychiatric comorbidities include major depression (up to $75 \%$, which is counted in our study as a subtype of PDD regarding the diagnostic entity introduced into DSM-5), anxiety disorders (up to $50 \%)$, personality disorders $(20-40 \%$ or more among those with early-onset PDD), somatoform disorders $(2.8 \%-45.2 \%)$, and substance abuse (up to 50\%) (Erkens et al., 2018 and Köhler et al., 2019). In our study, the comorbidity rate of Substance Use Disorder is less than western studies, this discrepancy may be due to sociocultural factors.

The presence of another disorder leading to the under recognition of dysthymia is a source of treatment error. There is a risk in paying attention predominantly to somatic or anxiety complaints of the patients, considering the depressive symptoms as a secondary reaction, instead of the main disorder (Vandeleur et al., 2017).

Even though, this findings are not new in scientific literature, this is the first description of such a new diagnostic entity in an Egyptian psychiatric population.

\section{CONCLUSION}

PDD was a highly prevalent psychiatric disorder rand may be masked by comorbid psychiatric disorders even MDD. These findings might promote psychiatrists to give more attention to PDD because of its impact on prognosis of other disorders and patients quality of life.

\section{REFERENCES}

1. Alhadi, A. N., Alateeq, D. A., Sharif, E. Al, Bawazeer, H. M., Alanazi, H., Alshomrani, A. T. and Alowaybil, R. (2017): An arabic translation, reliability, and validation of Patient Health Questionnaire in a Saudi sample. Annals of General Psychiatry, 1-9.

2. APA, American Psychiatric Association (2013): Diagnostic and Statistical Manual of Mental Disorders (DSM-5®). American Psychiatric Publishing, 168-171.

3. Brinkmann, E., Glanert, S., Hüppe, M., Moncada Garay, A. S., Tschepe, S., Schweiger, U. and Klein, J. P. (2019): Psychometric evaluation of a screening question for persistent depressive disorder. BMC Psychiatry, 19(1): 1-8.

4. Erkens, N., Schramm, E., Kriston, L., Hautzinger, M., Härter, M., Schweiger, U., and Klein, J. P. (2018): Association of comorbid personality disorders with clinical characteristics and outcome in a randomized controlled trial comparing two psychotherapies for early-onset persistent depressive disorder. Journal of Affective Disorders, 229: 262-268.

5. Guhn, A., Köhler, S., Brakemeier, E.-L. and Sterzer, P. (2019): Cognitive Behavioral Analysis System of Psychotherapy for inpatients with persistent depressive disorder: a naturalistic trial on a general acute psychiatric unit. European Archives of Psychiatry and Clinical Neuroscience, 1-11.

6. Hellerstein, D. J., Hunnicutt-Ferguson, K., Stewart, J. W., McGrath, P. J., Keller, S., Peterson, B. S. and Chen, Y. (2017): Do social functioning and symptoms improve with continuation antidepressant treatment of 
persistent depressive disorder? An observational study. Journal of Affective Disorders, 210: 258-264.

7. Ildirli, S., Şaır, Y. B. and Dereboy, F. (2015): Persistent depression as a novel diagnostic category: Results from the menderes depression study. Noropsikiyatri Arsivi, 52(4): 359-366.

8. Klein, D. N., and Black, S. R. (2013): Persistent depressive disorder-dysthymia and chronic depression. Psychopathology: History, Diagnosis, and Empirical Foundations, (9): 334-363.

9. Klein, J. P., Roniger, A., Schweiger, U., Späth, C. and Brodbeck, J. (2015): The association of childhood trauma and personality disorders with chronic depression: A cross-sectional study in depressed outpatients. The Journal of Clinical Psychiatry, 76(6): e794-801.

10. Köhler, S., Chrysanthou, S., Guhn, A. and Sterzer, P. (2019): Differences between chronic and nonchronic depression: Systematic review and implications for treatment. Depression and Anxiety, 36(1): 18-30.

11. Markkula, N., Suvisaari, J., Saarni, S. I., Pirkola, S., Peña, S., Saarni, S., Härkänen, T. (2015): Prevalence and correlates of major depressive disorder and dysthymia in an eleven-year follow-up - Results from the Finnish Health 2011 Survey. Journal of Affective Disorders, 173, 73-80.

12. Murphy, J. A. and Byrne, G. J. (2012): Prevalence and correlates of the proposed DSM-5 diagnosis of Chronic Depressive Disorder. Journal of Affective Disorders, 139(2): 172-180.

13. Nübel, J., Guhn, A., Müllender, S., Le, H. D., Cohrdes, C. and Köhler, S. (2020): Persistent depressive disorder across the adult lifespan: Results from clinical and population- based surveys in Germany. BMC Psychiatry, 20(1): 1-13.

14. Schramm, E., Klein, D. N., Elsaesser, M., Furukawa, T. A. and Domschke, K. (2020): Review of dysthymia and persistent depressive disorder: history, correlates, and clinical implications. The Lancet Psychiatry, 7(9): 801-812.

15. Vandeleur, C. L., Fassassi, S., Castelao, E., Glaus, J., Strippoli, M.-P. F., Lasserre, A. M., Preisig, M. (2017): Prevalence and correlates of DSM-5 major depressive and related disorders in the community. Psychiatry Research, 250: 50-58.

16. Ventriglio, A., Bhugra, D., Sampogna, G., Luciano, M., De Berardis, D., Sani, G. and Fiorillo, A. (2020): From dysthymia to treatment-resistant depression: evolution of a psychopathological construct. International Review of Psychiatry, 1-7.

17. Wenzel, A. (2017): Persistent Depressive Disorder. The SAGE Encyclopedia of Abnormal and Clinical Psychology, 5, 263276.

18. WHO. World Health Organization (2017): Depression and other common mental disorders: global health estimates. Geneva: World Health Organization, 1-24.

19. Wiersma, J. E., van Oppen, P., van Schaik, D. J. F., van der Does, A. J. W., Beekman, A. T. F., and Penninx, B. W. J. H. (2011): Psychological characteristics of chronic depression: a longitudinal cohort study. The Journal of Clinical Psychiatry, 72(3): 288-294. 


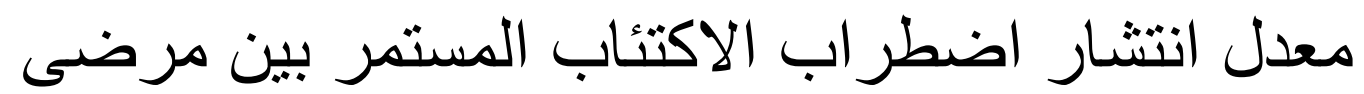

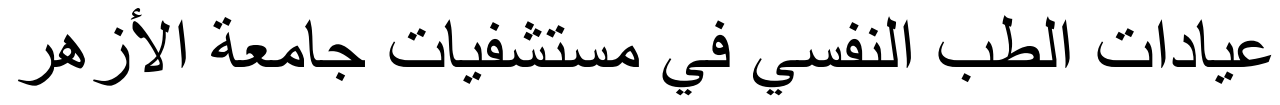
أحمد سعد حسانين يوسف، محمد أحمد لطفى كمال المهدي، محمد محمد علي الثيخ الثيخ قسم الطب النفسي، كلية الطب، جامعة الأزهر

E-mail: dr.a7medsa3d1409@gmail.com

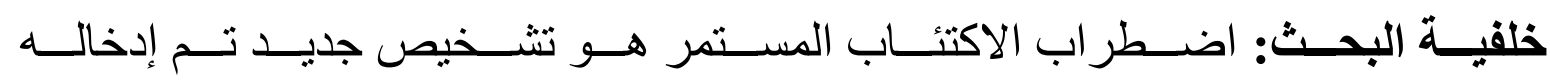

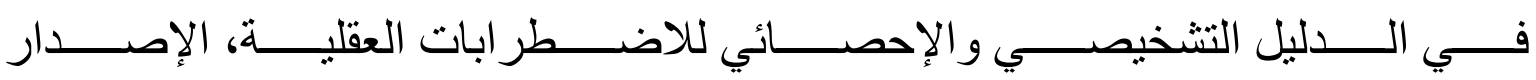

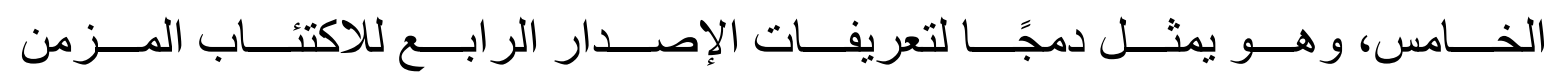

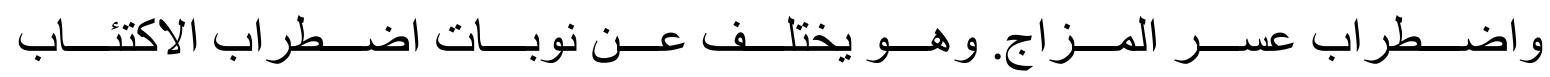

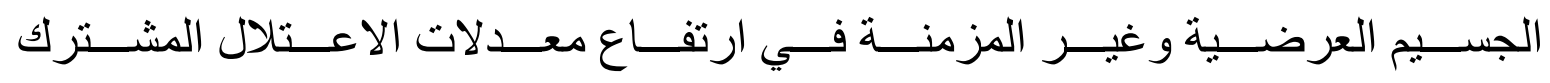

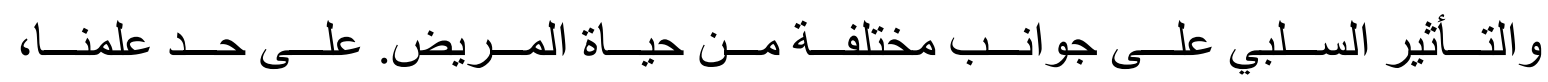

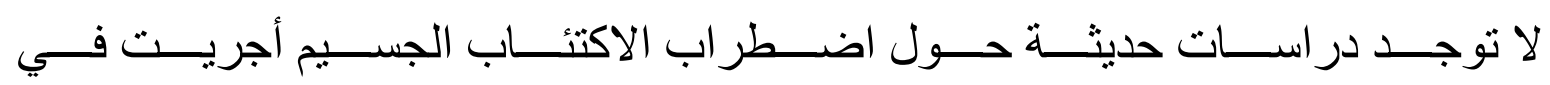

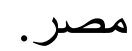

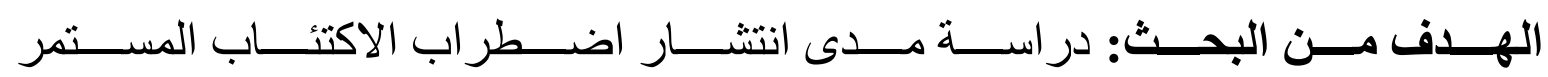

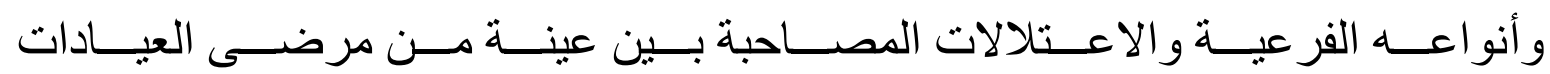
الخارجية للأمر اض النفسية بجامعة الأزهر.

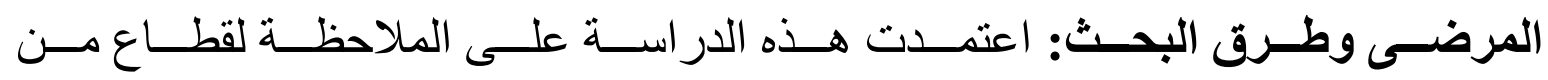

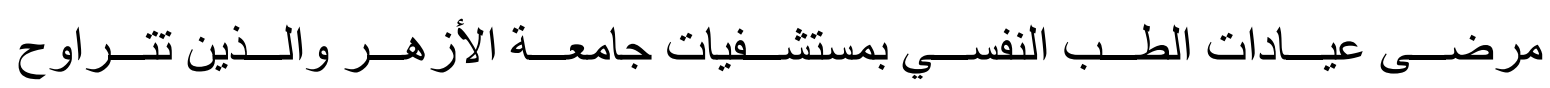

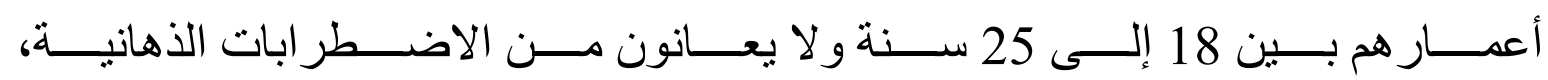

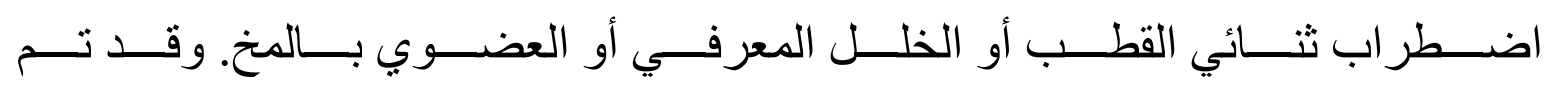

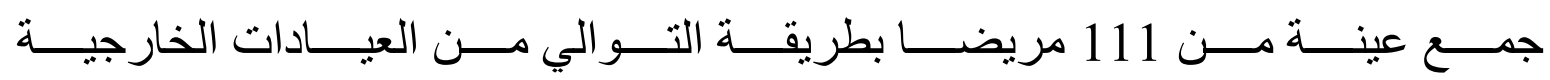

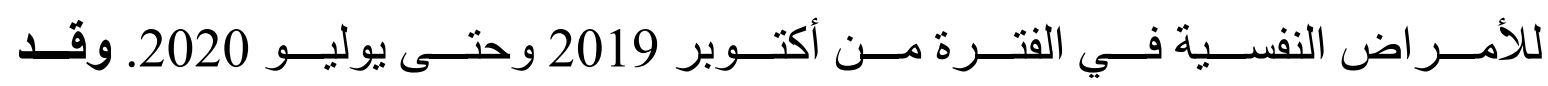

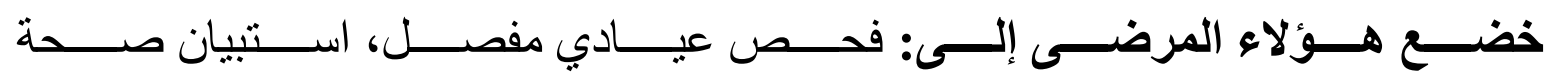
المريض-9 وفاحص الاكتئاب المستمر. 


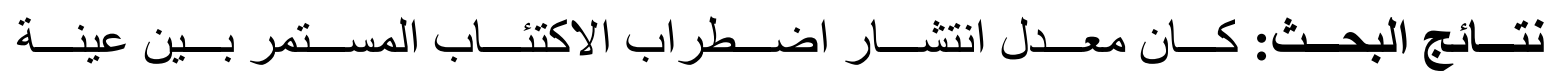

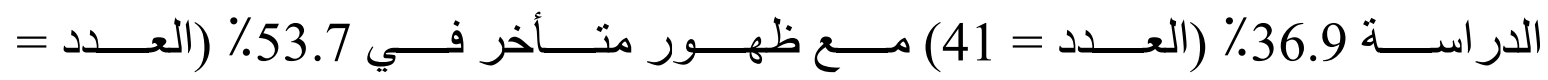

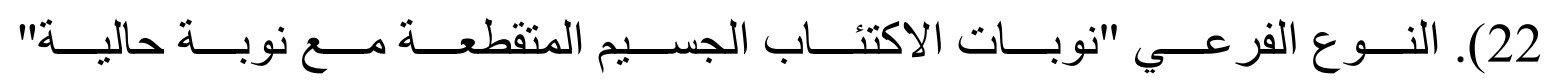

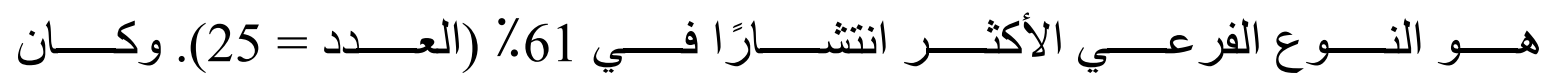

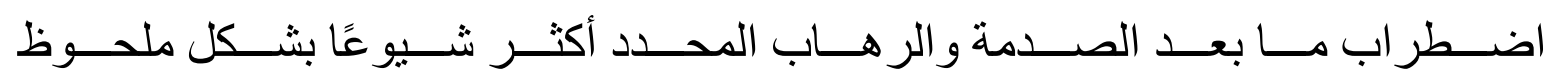

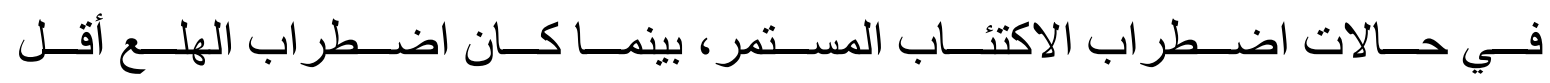
شيوعًا.

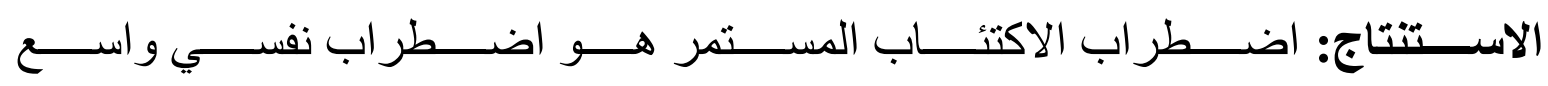

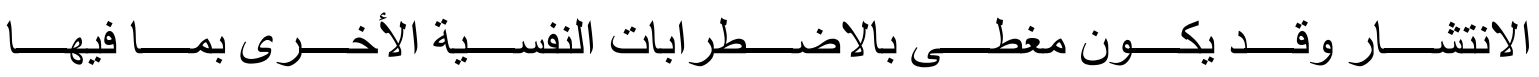

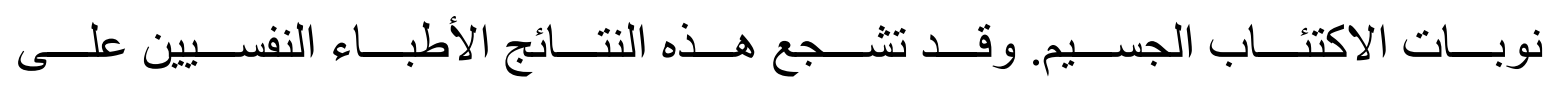

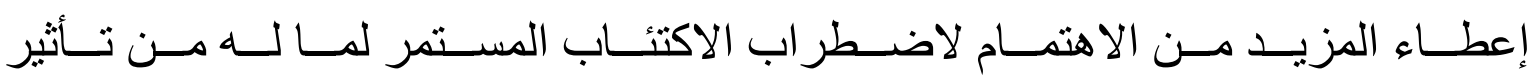
على تشخيص الاضطر ابات الأخرى وجودة حياة المرضى. 